Archivos de Criminología, Seguridad Privada y Criminalística

Año 8, vol. 17 Agosto-Diciembre 2021

ISSN: 2007-2023

www.acspyc.es.tl

\title{
El olvidado principio primum non nocere en el ejercicio del poder de criminalización
}

The forgotten primum non nocere principle in the exercise of criminalising power

Fecha de recepción: 03/10/2020.

Fecha de aceptación: 20/01/2021.

Dr. Gino Ríos Patio

Universidad de San Martín de Porres

griosp@usmp.pe

Perú

El autor aplica, en clave criminológica, la máxima latina que rige el ejercicio de la actividad profesional médica, a la acción estatal de convertir conductas en ilícitas y aplicar justicia penal, con la finalidad de analizar la manera, errada a su juicio, cómo el Estado ejerce el ius puniendi, violenta, arbitraria y perversamente, que trae como resultado un grave daño a la persona humana y la sociedad en su conjunto, como lo causa la iatrogenia clínica, que es un daño a la salud, causado o provocado por un acto médico, pero en este caso en una perspectiva que podría denominarse iatrogenia comunitaria, en tanto política legislativa, ejecutiva y jurisdiccional que fortalecen una estructura social patógena; y iatrogenia cultural, en tanto operatividad de un poder punitivo que marca y concluye la vida de las personas que tienen el infortunio de caer en su ámbito, lo que podría equiparar mejor ese poder punitivo a la mala praxis, pues se trata de un poder de criminalización monopólico con un accionar negativo, ineficiente e ineficaz, en la fase de definición, como en las fases de asignación o rotulación y de ejecución.

\section{Abstract}

The author applies, in a criminological key, the Latin maxim that governs the exercise of medical professional activity, to the state action of converting conducts into illicit and applying criminal justice, in order to analyze the way, wrong in his opinion, how the The State exercises the ius puniendi, violently, arbitrarily and perversely, which results in serious harm to the human person and society as a whole, as caused by clinical iatrogenesis, which is damage to health, caused or caused by a medical act, but in this case in a perspective that could be called community iatrogenesis, as a legislative, executive and jurisdictional policy that strengthen a pathogenic social structure; and cultural iatrogenesis, as the operation of a punitive power that marks and concludes the lives of people who have the misfortune of falling within their sphere, which could better equate that punitive power with malpractice, since it is a power of monopolistic criminalization with negative, inefficient and ineffective actions, in the definition phase, as in the allocation or labeling and execution phases.

\begin{tabular}{|c|c|c|c|}
\hline Palabras clave: & $\begin{array}{l}\text { Criminología cautelar; } \\
\text { Iatrogenia social y cultural; } \\
\text { Poder de criminalización. }\end{array}$ & Keywords: & $\begin{array}{l}\text { Prudential Criminology; Social } \\
\text { and cultural Iatrogenesis; Power } \\
\text { of criminalization. }\end{array}$ \\
\hline
\end{tabular}




\section{Introducción}

La locución latina primum non nocere significa lo primero es no hacer daño. Es un apotegma que expresa, como anota Aliaga, L. (2019), el pensamiento de que el médico cuando prescribe medicinas o aplica terapias, esto es, cuando atiende -para curar- al prójimo, debe tener como principio eliminar la contingencia de que surjan efectos accesorios o colaterales que dañen al paciente. Dicho aforismo pone de relieve, asimismo, la enseñanza de que la seguridad del paciente merece un protagonismo de primer orden como objetivo de salud y de política sanitaria y como factor de superlativa importancia en la particular característica de excelencia del servicio médico.

Dicha máxima ética de la profesión médica es un precepto fundamental que se enseña al estudiante de medicina, quien luego como profesional de la salud deberá meditar acerca de los posibles daños que puedan provocar sus acciones, pero también es un mandato cardinal en la vida democrática de un país que suele ser consagrado en su constitución política1.

El Juramento de Hipócrates contiene una expresión similar al mencionado adagio, en su cuarto párrafo se lee: Estableceré el régimen de los enfermos de la manera que les sea más provechosa según mis facultades y a mi entender, evitando todo mal y toda injusticia.

El arte de curar, prevaleciente en la Grecia clásica de Hipócrates, desde una concepción clínica², ya no mítico religiosa, era considerado una práctica médica de atención a los pacientes en su lecho de enfermedad, de ahí que la obligación responsable que asumía quien decidía medicinar a una persona, era proceder invariablemente en socorro y ayuda del otro, no en su perjuicio.

Aun cuando existen otras teorías modernas respecto al origen del axioma, como la que lo atribuye, según Herranz, G. (2002), al libro Physician and Patient (1847) de Worthington Hooker, quien le concede la paternidad de la locución al médico francés Auguste Francois Chomel; o la de Cedric Smith, según Smith, C. M. (2005), que la atribuye a Thomas Sydenham, como consta en un libro de T. Inman de 1860; es indudable que se trata de un pacto ético que el que cura asume responsable y voluntariamente ante la humanidad, evidentemente por la delicadeza incomparable de su ministerio terrenal.

${ }^{1}$ En el caso del Perú, el artículo 1 de la Constitución Política de 1993 preceptúa que la defensa de la persona humana y el respeto de su dignidad son el fin supremo de la sociedad y del Estado.

2 Según el Diccionario Etimológico Español en línea, la palabra clínica proviene del griego kliniké, forma femenina del adjetivo klinikós, formada por kline que significa cama y proviene del verbo klinein, que significa inclinarse o acostarse. 
El loable y nuclear talante de la ética médica radica, a juzgar por el Juramento de Hipócrates, en asumir humana y técnicamente la esencial y vital pre disposición al auxilio hacia el prójimo enfermo, hacia el que sufre. Es la expresión de la filantropía griega, la manifestación auténtica del amor al hombre como cimiento del amor al arte, en este caso, a la medicina, al arte de curar. Debido a este noble sentimiento, el médico elije rectamente el mejor recurso a su alcance y respeta la dignidad y el honor del paciente. En ese sentido, se explica también el sigilo de la profesión médica, cuyo basamento es que nadie sepa que el paciente tiene una desarmonía en su naturaleza. En definitiva, el principio ético médico primum non nocere apunta a evitar el sufrimiento del paciente y respetar su dignidad humana.

Análogamente, cuando la disconformidad se da no en la naturaleza humana sino en el cuerpo social, ocasionando que una persona infrinja el orden establecido debido a la injusticia e inequidad de las estructuras tanto económica como cultural y política, que lo excluyen, relegan y discriminan en las oportunidades necesarias para la consecución de su proyecto de vida; le imponen normas jurídicas en cuya formación no ha intervenido; y hacen que sea considerado un enemigo, un extraño u otro diferente y de ninguna o de una menor consideración en la sociedad; es razonable que resulta necesario reestructurar la sociedad y el Estado, pero mientras tanto, pues son tareas de largo plazo, es imprescindible dispensarle un tratamiento igual a los demás miembros de la sociedad, esto es, de respeto a su dignidad, no solo porque así lo manda el precepto jus antropocéntrico de la Constitución Política, que enuncia que el fin supremo de la sociedad y del Estado es la defensa de la persona humana y el respeto de su dignidad, sino porque es un semejante, una persona igual a todas.

No es sensato, asimismo, castigarlo, peor aún hacerlo draconianamente, pues a nadie se le corrige a palos y carece de base ética castigar en una sociedad de desiguales, toda vez que donde no hay similitud social, no puede haber castigo legítimo. Hacerlo cumplir el castigo en condiciones infra humanas, como son, la sobrepoblación y el hacinamiento del establecimiento carcelario, resulta también irreflexivo. En la misma línea, mantenerlo socialmente en la condición de infractor castigado más allá del tiempo de su condena, sin rehabilitación ni resocialización alguna, condicionándolo a la reincidencia y habitualidad, deviene perverso e ilegítimo.

En este panorama, las acciones del sistema punitivo formal se encuentran horras de filantropía y las acciones del control social informal carentes de empatía. El Estado y la sociedad causan grave daño a la persona que infringe el orden establecido, lo cual no quiere decir en modo alguno que no sea sancionada, sino antes bien que debe haber una política 
criminológica de prevención en sus tres niveles: primario a través de políticas sociales; secundario mediante la vigencia real y efectiva de las garantías procesales y los principios penales; y terciario vía una política penitenciaria que asegure la rehabilitación, reeducación y resocialización del infractor. Este modo de proceder del poder punitivo que monopoliza el Estado y ejerce cotidianamente con una mala praxis, refuerza las injustas y desiguales estructuras y termina literalmente con la vida de las personas vulnerables, marginales y de escasos recursos que constituyen, casi unánimemente, la carne de presidio de la fábrica penal.

El presente estudio muestra y analiza algunos de los daños más graves que ocasiona el ius puniendi al ejercerse sin ningún respeto a la dignidad de la persona humana, con el propósito de alumbrar este espacio ensombrecido por la iniquidad y el abuso contra la persona considerada desigual, para ejercer su defensa como ordena la Constitución Política, llamando a la reflexión para que las acciones de la sociedad y el Estado se guíen por la empatía y la filantropía, al estilo del espíritu que inspira la máxima médica primum non nocere, de neta aplicación a la actividad de las agencias penales y a cualquier profesión.

\section{El poder de criminalización}

El Estado posee el poder de criminalizar conductas; determinar las reglas en virtud de las cuales se debe llevar a efecto un proceso para imputar, investigar, probar y establecer la responsabilidad por la infracción cometida; e imponer y ejecutar sanciones penales. Dicho poder lo ejerce a través del órgano legislativo, mediante la dación de leyes; de las agencias penales, como son la Policía Nacional, el Ministerio Público, el Poder Judicial, para la aplicación de la ley; y del órgano encargado de administrar los establecimientos carcelarios, para la ejecución de la misma.

La forma y el contenido de cada uno de esos actos estatales, como la de los demás de la misma índole, está prescrita en la Constitución Política, la cual consagra además los derechos fundamentales, las libertades y garantías de las personas, y los principios penales, de acuerdo con el sistema político adoptado por la comunidad nacional fundante, entre otros aspectos.

Así, en un sistema democrático, la Constitución Política preceptúa que el poder emana del pueblo, no solo para la elección de las autoridades principales, sino también para la participación, la deliberación, el control y la fiscalización política, actividades esencialmente democráticas que ya no solo se realizan mediante los partidos políticos, sino fundamentalmente a través de los mass media, las movilizaciones, el activismo, las 
organizaciones no gubernamentales y cualquier otro medio de expresión directa de la población.

Teniendo en consideración que el Estado como expresión de poder y soberanía, que le viene de la población, cuenta con el máximo poder y la mayor capacidad de fuerza que se manifiesta en la coacción de las normas que emite, las cuales en el ámbito penal configuran especialmente la tensión dialéctica entre la libertad del hombre y el poder público; la dación de esas normas penales tiene necesariamente que producirse por el órgano legislativo, que simboliza políticamente la representación nacional; además, tiene que permitir la deliberación pública para que el sentido final y finalidad de su mandato sea genuinamente legítimo.

El proceso de criminalización es, entonces, el conjunto de actos políticos, jurídicos y sociales del Estado, que convierten una conducta en ilícita, mediante la dación de una norma y la aplicación de una política penal específica, esto es, un proceso de construcción político social del crimen y del criminal. Sin lugar a dudas, es posible afirmar que el ejercicio del ius puniendi es político, por lo que se puede apreciar en la selectividad y discriminación del sistema penal, cuyo ámbito de aplicación recae en los grupos vulnerables, carenciados y marginales, que constituyen asimismo la casi unanimidad de la población penitenciaria de cualquier país latinoamericano. Y la política no es una actividad que se ejerza rectamente por estos lugares.

\section{El poder de definición, sus yerros y el grave daño que ocasiona}

En ese conjunto de actos políticos, jurídicos y sociales del Estado, que transforman un comportamiento de lícito en ilícito, el poder de definición está dado por la dación de la norma penal, acto político indudable, que tipifica un comportamiento como delito; por lo que debe estar a cargo del órgano legislativo y sometido al imperio de los derechos humanos y los principios jurídicos, porque la sociedad y el Estado deben respetar la dignidad de la persona del infractor y defenderla de la arbitrariedad y el abuso del poder, para que una vez probada su responsabilidad se le pueda sancionar con equidad y razonabilidad por la gravedad y lesividad de su acto.

Como anota Serrano, A. (2004) el poder de definición supone el inicio del proceso político de construcción social del crimen y del criminal. El poder, a través del Estado y la sociedad, construye su propio concepto de desviación primaria y mediante la correspondiente política penal trata y define socialmente como criminal -aplicación de la ley penal- a ciertas 
personas, principalmente de los sectores vulnerables y marginales, quienes asumen su condición de criminal y pasan a comportarse como tal, lo que se conoce como desviación secundaria.

Pues bien, lo primero que debe tener en cuenta el poder de definición es no extralimitarse en su ejercicio. De acuerdo con el principio penal de última ratio, que traduce el principio de estricta necesidad de la intervención penal o de mínima intervención, basado en la utilidad social general del menor costo versus el mayor fin intimidatorio, los presupuestos axiológicos de un Estado social y democrático de Derecho presentes en la Constitución acuden a concretar esta importante limitación del ius puniendi, a fin de que la intervención penal sea legítima y no genere un expansionismo y una hipertrofia del Derecho Penal, que deviene siempre en manipulación política y termina imponiendo como valores, los intereses particulares de grupos y no el interés general o común de la población.

Entre las herramientas de control social formal con que cuenta el Estado, la norma jurídico penal es -y debe serlo- la última ratio, porque dado el enorme poder de la violencia estatal que se ejerce a través de la persecución penal, debe hacerse un uso prudente y mesurado de ella, como apuntan Maurach, R. y Zipf, H. (1994)

Sin embargo, del cuadro de modificaciones al Código Penal que obra en el Sistema Peruano de Información Jurídica, aparecen grosso modo, 802 modificaciones en 30 años de vigencia, de lo que resulta 27 modificaciones por año aproximadamente, lo que equivale a algo más de dos modificaciones mensuales, esto es, una cada 15 días, en promedio, con lo cual queda demostrado en este aspecto una producción penal fabril que expande e hipertrofia el sistema penal, la mayoría de las cuales no se ha generado mediante una ley, sino a través de un decreto legislativo, que si bien es una norma que tiene fuerza de ley, ha sido elaborada por el Poder Ejecutivo, propiamente en el Ministerio de Justicia, y no en el Parlamento Nacional por los representantes del pueblo, lo que en principio dice mal de su legitimidad, que es el principal requisito de toda norma que pretende regular la vida social y sancionar conductas humanas.

En este universo de modificaciones al Código Penal, se crean nuevos tipos penales, se modifican los presupuestos fácticos de los existentes, se agravan las penas y se reducen o eliminan beneficios. 
Además de la flagrante trasgresión del principio de última ratio, estricta o mínima intervención del derecho penal, y del principio de reserva de ley penal, algunas de las modificaciones también violan el principio de tipicidad o taxatividad.

En efecto, este principio exige al legislador que las normas penales sean claras y precisas, a fin de que su aplicación no sea una fuente de problemas para las agencias penales y eviten el uso de la analogía, así como para los ciudadanos, a fin de que conozcan clara y plenamente lo que se puede y no se puede hacer, con lo cual tendrían mayor seguridad jurídica. Es la exigencia de la denominada ley cierta y ley estricta, que contienen un mandato de determinación de la ley, de máxima trascendencia cuando dicha ley permite limitar, restringir o suspender derechos fundamentales, lo cual supone que en aquello que se trasmite a los ciudadanos exista convicción y certeza, para que pueda ser cumplido. No deben existir cláusulas generales como atentar contra el orden social democrático ni conceptos jurídicos indeterminados en las normas penales, tales como interés público, identidad cultural o étnica, orden público, perturbación de la paz, de catástrofe o de graves circunstancias que afecten la vida de la Nación, comportamiento indigno, desvalorización en el concepto público, menoscabo de la imagen pública, transparencia de la función pública, decoro del cargo, entre otras.

Todas esas modificaciones, no obstante, se anuncian en pro de la seguridad ciudadana, sin embargo, todas dañan a la persona humana, porque agravan su situación frente al ius puniendi.

\section{El poder de asignación o rotulación, sus dislates y el grave deterioro personal que ocasiona}

Es a través de las agencias penales de persecución, como la policía y la fiscalía; y de juzgamiento, como el poder judicial, que se ejerce este poder de asignación o rotulación, etiquetando al infractor mediante una aplicación desigual y arbitraria, desproporcionada, de la ley penal, que como hemos visto adolece del cumplimiento de los principios antes referidos; y estigmatizándolo perpetuamente a nivel social.

García Pablos de Molina, A. (2000) señala al respecto que:

El principio de proporcionalidad rechaza el establecimiento de conminaciones legales (proporcionalidad en abstracto) y la imposición de penas (proporcionalidad en concreto) que carezcan de relación valorativa con el hecho cometido, contemplado éste en su significado global. Tiene en consecuencia, un doble destinatario: el poder legislativo (que ha de establecer 
penas proporcionadas, en abstracto, a la gravedad del delito) y el judicial (las penas que los jueces impongan al autor de un delito han de ser proporcionadas a la concreta gravedad de éste)... la exigencia de proporción se determina mediante juicio de ponderación ente la carga coactiva de la pena y el fin perseguido por la conminación legal. (pág. 289)

De lo que desciende claramente que las limitaciones punitivas, provenientes de la razonabilidad y la proporciomnalidad, deben existir en la interpretación y la aplicación del Derecho Penal, así como en la construcción de la norma misma, a fin de que no se incurra en exacerbación punitiva sino en prudencia y cautela, como lo aconseja Zaffaroni, E. (2011).

En ese sentido, el principio de proporcionalidad penal se concreta en los sub principios de fragmentariedad $y$ de subsidiaridad, que imponen al legislador que no sancione penalmente todo tipo de conductas, como el adulterio por ejemplo; y que sólo sancione las formas más graves de vulneración de los bienes jurídicos, a fin de que exista precisamente proporcionalidad en la aplicación del Derecho Penal, como apunta Rosales, D. (2008).

En un Estado democrático y de Derecho la reafirmación y consagración del principioderecho de dignidad humana, hace que el orden político, ergo, el poder de criminalización y también el orden jurídico, se fundamenten en los derechos humanos, por ello es que el derecho penal liberal es de acto y no de autor, pues estaría horro de justificación material.

El poder de asignación o rotulación, sin embargo, no suele guiarse por la menor intervención posible en la vida de los ciudadanos, ni por la proporcionalidad y razonabilidad en la aplicación de la norma penal, como consecuencia de un poder de definición hipertrofiado. En otras palabras, el expansionismo penal se traduce en una aplicación irrestricta, desigual y arbitraria de la ley penal, contrariamente a lo que señalaba Beccaria, C. (1994):

para que la pena no sea violencia de uno o de muchos contra un particular ciudadano, debe esencialmente ser pública, pronta, necesaria, la más pequeña de las posibles en las circunstancias actuales, proporcionada a los delitos, dictada por las leyes. (pág. 68 y 69)

De hecho, se advierte que la necesidad de la ley penal, aspecto vinculado al principio de mínima intervención, es una condición indispensable de la proporcionalidad penal en abstracto y en concreto, aspecto vinculado a la aplicación de la ley penal, que la Declaración de los Derechos y Deberes del Hombre y del Ciudadano de 26 de agosto de 1789 ya había señalado en su artículo 8 en el sentido que la ley no debe establecer sino las penas estrictas y evidentemente necesarias. 
El Derecho Penal busca la paz jurídica para lo cual regula conductas humanas, lógicamente dentro de un esquema de racionalidad, lo que es contradictorio con la actual tendencia de la política penal de extremar la intervención penal, pese a que el sistema penal tiene reglas para medir y ponderar la aplicación de la pena, por ejemplo, en los artículos 45 y 46 del Código Penal peruano.

La sensación de justicia, de gran significación para afirmar la conciencia penal, afirma Roxin, C. (1997) exige que nadie pueda ser sancionado más rígidamente que lo que se merece, esto es, con una pena acorde con la culpabilidad.

Uno de los casos que ejemplifica palmariamente un ejercicio desigual y arbitrario del poder de asignación o rotulación es la Ley $N^{\circ} 29409$ de 16 de setiembre de 2009 sobre reincidencia y habitualidad, que las considera agravantes de la responsabilidad penal, con lo cual sale de la esfera del derecho penal de acto para insertarse en la del derecho penal de autor, selectivo y discriminatorio, en virtud del cual de manera irracional el Estado se muestra fuerte y poderoso frente a los ciudadanos, es decir, sin escrúpulos para hacerles daño también en esta fase de la criminalización.

\section{El poder de ejecución, sus errores y el grave detrimento personal que ocasiona}

El poder de ejecución penal sigue invariablemente la senda desviada marcada por el poder de asignación o rotulación y por el poder de definición, porque de esa manera el poder de criminalización configura un espacio propicio para sus fines de control y dominación vertical y militarizada de las personas, que no es otro que el sistema penal, cuyas agencias policial, fiscal, judicial y penitenciaria, actúan no solo ilegítimamente, que como se ha visto anteriormente es la falla de fábrica que tienen, sino también ilegal y no armónicamente en sí mismas y entre ellas, pues al amparo de una mal entendida independencia e imparcialidad, interpretan y aplican la norma conforme a criterios ajenos a lo penal, como es el caso, entre otros, del factor mediático al que algunos agentes penales sucumben por filia o por fobia.

Actúan también falazmente, pues su actividad no logra coadyuvar a los fines que dice aspirar la pena, como son, la prevención general y la prevención especial, esta última a través de la reeducación, resocialización y reintegración a la sociedad, que son desmentidos, respectivamente, por los índices de criminalidad y de victimización y por la tasa de reincidencia criminal, todas las cuales exceden del 30\% según informes del Instituto Nacional de Estadística e Informática y del Instituto Nacional Penitenciario, en lo que respecta a la 
criminalidad aparente, que es la que se denuncia y sanciona, no así en cuanto a la criminalidad real.

Por último, actúan asimismo con carácter alucinante, pues su operatividad magnificada por los medios de comunicación social por conveniencia a sus propios intereses, explicada en lo que se ha venido en denominar la criminología mediática ${ }^{3}$, genera la falsa creencia popular de que, a penas más duras, menos delitos, cuando en realidad la ecuación se presenta al contrario, sencillamente porque la causa de la criminalidad reside, de acuerdo con la criminología crítica contemporánea, en las injustas, arbitrarias, desiguales y excluyentes estructuras económica, política, social y cultural, respectivamente.

Entonces, ante el efecto creado por los mass media, consistente en una fuerte impresión cotidiana generada por la cobertura repetida varias veces en el día de los actos delictivos, se causa un cambio de la perspectiva racional y serena con el que debería hacerse el análisis de la cuestión criminal, por un tono afectivo-emocional, generalmente eufórico, que produce alteraciones en la percepción, en especial visiones, como la que hace ilusionar de que el derecho penal es la solución para reducir y controlar el crimen, olvidando que para buscar soluciones en materia criminal, tienen más fuerza las políticas sociales que el Código Penal.

El daño que el ejercicio de este poder hace a la persona humana es ingente y grave, basta tener en cuenta la magnitud de la población penitenciaria y la condición de sobre población y de hacinamiento en el Perú por ejemplo, según cifras del Instituto Nacional Penitenciario.

\section{Criminología cautelar}

Zaffaroni, E. (2011) señala que "la contabilidad cadavérica, descontando los muertos por las guerras y los causados por negligencia, demuestra que los estados cometieron más homicidios dolosos que todos los restantes homicidas del planeta" (p. 447). Agrega que, dada la indefensión de las víctimas, esos homicidios fueron más graves por ser alevosos.

Habría que agregar que si ampliamos el concepto de muerte y consideramos dentro de este conjunto la situación de sobrevivencia, subsistencia, exclusión e invisibilidad que

3 Se denomina criminología mediática a la actividad de los mass media constructora de la cuestión criminal, a través del uso pre determinado y tendencioso del lenguaje y las imágenes, hasta presentarla como la única razón de los males sociales, activadora de la demanda social y la respuesta penal emocionales, productora de la normalización de la violencia, la mediatización del miedo y la preeminencia artificial de la seguridad ciudadana aún por encima de los derechos y libertades individuales. 
padecen las personas carenciadas, vulnerables y marginales, de donde el sistema penal extrae a los delincuentes que sobre pueblan las cárceles, entonces la contabilidad se incrementa exponencialmente, como puede advertirse fácilmente del índice de pobreza multidimensional en el mundo, que asciende a 1,300 millones de personas, según el Programa de las Naciones Unidas para el Desarrollo (PNUD), el cual analiza 105 países, abarca casi las tres cuartas partes de la población mundial y mira más allá de los ingresos para comprender cómo las personas experimentan la pobreza de manera múltiple y simultánea, por lo que comprende dimensiones tales como salud, educación, nivel de vida, falta de acceso a agua potable, nutrición adecuada, educación primaria, mortalidad infantil, vivienda, bienes y electricidad.

Frente a un panorama tan grave, se visualiza claramente como los intereses individuales que dirigen la vida del ser humano, que hoy en día están condicionados por la proclividad al dispendio descomunal e innecesario de bienes y productos, sobre la base ficticia de aparentes necesidades, incitada por la globalización, la tecnología de uso masivo y el neoliberalismo; generan un individualismo narcisista exacerbado, que es altamente criminógeno, por cuanto busca la satisfacción inmediata y automática de sus intereses, sin ninguna consideración al prójimo, lo cual crea conflictividad pues siempre los recursos son escasos en comparación con la cantidad de personas, la misma que se resuelve a través de la imposición de la fuerza apareciendo así el comportamiento violento interpersonal que es el crimen.

Este iter criminis está facilitado por las injustas, arbitrarias, desiguales y excluyentes estructuras del sistema económico, sin políticas públicas o con insuficientes programas en favor de las personas más necesitadas; del sistema político, con dación, aplicación y ejecución de leyes sin participación de la población y en perjuicio de las clases más necesitadas; del sistema social, con una consideración del éxito personal de carácter exclusivamente materialista, en función del ingreso dinerario y el patrimonio que se posee; y del sistema cultural, con una dinámica discriminatoria y racista de raíz colonial. Todo lo cual perdura por la eterna ausencia del Estado y por su puesta al servicio de intereses particulares y de grupo, que lo alejan del bien común y el interés general.

Ya el pensamiento de René Girard, analizado por Rozzi, M. (2010), ilustra en el sentido que el hombre tiene que construir un sistema civilizado para dar curso a una violencia socialmente aceptada, lo que constituye una verdadera contradicción inherente a su naturaleza social; y que ese sistema además contiene un mecanismo de competición violento que acalla la violencia originaria o desnuda, para disimularla en formas sofisticadas de 
violencia, lo que es un rito presente en las instituciones económico-políticas, como la capitalista contemporánea.

En una sociedad política y jurídicamente organizada, como es el Estado, esa violencia sagrada y ritual, ejercida oficialmente por éste con el nombre de violencia legítima, que crea enemigos en los miembros más vulnerables de la sociedad, no consigue quebrar la órbita de la violencia originaria, sino que la reinicia, generando una situación de crisis social recurrente que la empuja hacia su ruina total.

Por otro lado, poner al Estado al frente del ejercicio del ius puniendi, es decir, del poder punitivo, de la violencia oficial, con carácter monopólico, exclusivo y excluyente, es igual que asignar al zorro la tarea de cuidar el gallinero, para usar una expresión coloquial pero ilustrativa de la situación.

Ahora bien, si la violencia, cualquiera que fuere, es irracional ¿será posible dotarla de racionalidad? Vemos cómo la dogmática penal se esfuerza en teorizar para fundamentar doctrinariamente la normatividad que el poder de criminalización emite, pero tratemos de recordar si alguna vez el finalismo, el funcionalismo o el causalismo contribuyeron a reducir la criminalidad. 0 si las teorías retribucionistas o utilitaristas de la pena logran legitimarla en una sociedad de desiguales o justificar su finalidad prevencionista.

El quehacer que tenemos por delante para cambiar esta situación dañosa para el hombre es la aplicación de la criminología crítica para desmontar las ideas neutralizadoras de la violencia estatal, demostrando que el sistema penal, el ius puniendi, es dirigido por el poder y enfilado contra todo aquel que moleste o sea contrario a sus intereses hegemónicos. En esta línea, anular con estudios y estadísticas reales la información de los mass media que crea ex profesamente una cuestión criminal conveniente para que el poder siga creando crímenes y criminales; y proponer programas y métodos para prevenir la conflictividad y la violencia en la interacción humana.

Además, se requiere la contribución del jurista penal para que no proporcione el discurso legitimador-justificador de la violencia, que está siendo entendido, legitimado y consentido en este siglo XXI desde el poder y como maniobra política acreditadora de intervenciones nacionales e internacionales, lo que resulta en una dignificación de los conflictos, precisamente porque el odio viene impulsado por un discurso y una retórica emocional que regresa al hombre a su origen pre racional, como sostiene Sierra, A.(2007). 
Dadas las circunstancias históricas anotadas, es imprescindible y urgente activar la criminología cautelar para prevenir, alertando sobre la extra limitación del poder punitivo, para que el sistema penal sea usado de manera sensata y en extremo prudente, sujeto a los derechos, libertades y garantías fundamentales y los principios penales universales. Una criminología de los derechos humanos, de la liberación del yugo del poder, una criminología que sea el control de los controles, que controle al poder punitivo y al sistema penal, para que no hagan daño a la persona.

\section{Conclusiones}

El poder de criminalización busca legitimarse-justificarse en sí mismo. Esto es un dato histórico, así ha ocurrido desde que esa forma jurídico política social monopolizó el poder de castigar. Dibuja un círculo cerrado impenetrable sin referencia ni límite alguno. Desprecia cualquier conocimiento científico, porque es un fenómeno de hecho, con vocación hegemónica. Esta ontología del poder deriva consecuentemente en un pan penalismo, neo punitivismo y en la hipertrofia del derecho penal, un expansionismo punitivo que es fundado en el odio contemporáneo inoculado por el discurso retórico dirigido a la población para que clame venganza y duro castigo contra los enemigos creados por el poder, de tal modo que cualquier intento desde la academia de criticar y racionalizar el sistema penal es calificado de anti sistema.

La criminalización desde el poder fabrica enemigos y crea crímenes y criminales para perpetuar un sistema de control y dominación que le permita eternizarse, como un medio instrumentalizado y potenciado por el discurso al servicio del fin que persigue.

La realidad, inmarcesible y dinámico continente en el cual todo se presenta, no puede ser abarcada plenamente por la teoría. La realidad en la que se genera la criminalidad no puede, por ende, ser asida por la dogmática ni la normatividad penal. Aquella es un mero discurso legitimador de ésta.

En la cuestión criminal, la única realidad que cuenta en verdad son los cadáveres y los ciudadanos supérstites -cadáveres postergados- que carecen de una vida digna y compatible con la condición humana. Ambos aspectos de la realidad deben ser percibidos por la criminología y deben merecer su atención, como ciencia de la vida que es.

Reducir la criminalidad y propiciar un mejor control social, son tareas de la criminología en general. Atajar la violencia estatal ejercida a través del poder de criminalización; anular el efecto demencial que causan los mass media y el discurso retórico sobre el crimen y los 
criminales; y estar alerta y prestar la atención debida frente a la actividad punitiva del poder, denunciando, criticando y reclamando prudencia en el uso del poder de castigar, para que no se extralimite, desvíe ni continúe abusivo ni arbitrario, y para reformar el sistema penal, es el trabajo de la criminología cautelar.

Esta criminología prevencionista y vigilante que se propone, contribuirá al diseño de una política criminológica más eficiente y eficaz, para que el derecho penal no sea, como señaló Franz Von Liszt, citado por Roxin, C. (1972), una infranqueable barrera de ordenación positivista y elaboración sistemático conceptual de los presupuestos del delito, que impide aplicar los principios criminológicos del tratamiento conveniente de la conducta desviada, basados en fundamentos empíricos -no en abstracciones teoréticas, ajenas a la acción y la práctica- que se materializan en métodos sociales.

El Derecho Penal debe ser la Carta Magna de la persona que tiene un comportamiento criminal, como lo quiso el eminente jurista austríaco alemán, ello hará posible la vigencia del preterido principio primum non nocere, cuyo olvido deliberado por el poder de criminalización lo primero que hace es dañar a la persona humana.

Lo que planteamos es asumir la cuestión criminal con empatía, para ubicarnos en el lugar del otro, y de esa manera prevenir socialmente el crimen y la criminalización del comportamiento con el auxilio de la criminología, mediante una eficaz política criminológica de hondo contenido y responsabilidad social del Estado, modificando estructuras y sistemas, para comprender más y castigar menos, puesto que nadie se enmienda a golpes.

En otras palabras, las cosas deseadas en este artículo, la desiderata en materia de cuestión criminal, es incitar a que el poder estatal se cure a sí mismo -cura te ipsum- practique una introspección y observe sus defectos y virtudes con relación a la atención y consideración a los ciudadanos, antes de castigarlos y hacerles daño con su poder penal. Creo que todos, que formamos el Estado, debemos hacer esa saludable reflexión.

\section{Lista de referencias}

Aliaga, L. (2019). Primum Non Nocere. SEMERGEN. 45(1): 4-5.

Beccaria, C. (1994). De los delitos y de las penas. Bogotá: Universidad Externado de Colombia.

Asamblea Constituyente francesa (1789). Declaración de los Derechos y Deberes del Hombre y del Ciudadano de 26 de agosto de 1789. http://www.ub.edu/ciudadania/hipertexto/evolucion/textos/humano1789.htm 
Diccionario Etimológico Español en línea (s/f). Diccionario. http://etimologias.dechile.net/ García, A. (2000) Derecho Penal. Introducción. Madrid: Facultad de Derecho de la Universidad Complutense.

Herranz G. (2002) The origin of "Primum non nocere". BMJ rapid-response. https://www.bmj.com/rapid-response/2011/10/29/origin-primum-non-nocere

Instituto Nacional de Estadística e Informática (2019). Estadísticas de Seguridad Ciudadana (2019). http://m.inei.gob.pe/biblioteca-virtual/boletines/estadisticas-de-seguridadciudadana/1/\#lista

Instituto Nacional Penitenciario (2019). Informe Estadístico 2019. https://www.inpe.gob.pe/normatividad/documentos/4295-informe-estadísticodiciembre-2019/file.html

Juramento de Hipócrates (s/f). http://www.sld.cu/galerias/pdf/sitios/bmn/hipoc_jur.pdf

Maurach, R. y Zipf, H. (1994) Derecho penal. Parte General. Ted. Traducido por Bofill, Jorge/Aimone, Enrique. Buenos Aires: Editorial Astrea.

Ministerio de Justicia y Derechos Humanos (2018). Sistema Peruano de Información Jurídica. Constitución Política del Perú de 1993. Décimo primera edición oficial. https://www.minjus.gob.pe/wp-content/uploads/2018/06/4-Constituci\%C3\%B3n-

Pol\%C3\%ADtica-del-Per\%C3\%BA-\%E2\%80\%93-D\%C3\%A9cimo-Primera-

Edici\%C3\%B3n-Oficial.pdf

Programa de las Naciones Unidas para el Desarrollo (2018). Más allá del ingreso. Un perfil de la pobreza. Índice Multidimensional de Pobreza 2018. https://feature.undp.org/multidimensional-poverty/es/

Rosales, D. (2008). El principio de proporcionalidad y la limitación de la pena. En Jurisprudencia Penal Comentada, Tomo 173, abril 2008, 105-106.

Roxin, C. (1972) Política criminal y sistema del Derecho Penal. Traducción e introducción de Francisco Muñoz Conde. Barcelona: Bosch.

Roxin, C. (1997) Derecho Penal parte General. Tomo I. Fundamentos. La estructura de la teoría del delito. Traducción Diego Manuel Luzón Peña/Miguel Díaz y García Conlledo/Javier de Vicente Remesal. Madrid, España: CIVITAS. 
Rozzi, M. (2010). La interpretación filosófica y política de la violencia y lo sagrado de René Girard y su influencia en la antropología latinoamericana. Universitas Philosophica 55, año 27: 67-74.

Serrano, A. (2004). Introducción a la criminología. Madrid: Dykinson

Sierra, Á. (2007). Los discursos del odio. Cuadernos del Ateneo. Humanidades. https://webcache.googleusercontent.com/search?q=cache:14a3Fm3I_CMJ:https://dial net.unirioja.es/descarga/articulo/2604988.pdf $+\& c d=3 \&$ hl=es\&ct=clnk\&gl=pe

Smith, C. (2005). J. Clin. Pharmacol. 45: 371-377, 2005, April issue "Origin and Uses of Primum non nocere, Above all, do no harm!" https://www.google.com/search?q=Smith\%2C+C.+M.+J.+Clin.+Pharmacol.+45\%3A+37 $1 \% \mathrm{E} 2 \% 80 \% 93377 \% 2 \mathrm{C}+2005 \% 2 \mathrm{C}+$ April+issue+\%220rigin+and+Uses+of+Primum+no $\mathrm{n}+$ nocere $\% 2 \mathrm{C}+$ Above+all\%2C+do+no+harm!\%22.\&oq=Smith $\% 2 \mathrm{C}+\mathrm{C} .+$ M.+J.+Clin.+Phar macol. $+45 \% 3 \mathrm{~A}+371 \% \mathrm{E} 2 \% 80 \% 93377 \% 2 \mathrm{C}+2005 \% 2 \mathrm{C}+$ April+issue $+\% 220$ rigin + and $+\mathrm{U}$ ses+of+Primum+non+nocere $\% 2 \mathrm{C}+$ Above+all\%2C+do+no+harm!\%22.\&aqs=chrome..69 i57.1279j0j7\&sourceid=chrome\&ie=UTF-8

Zaffaroni, E. (2011). La palabra de los muertos. 1a. Edición. 1a. EDIAR. Buenos Aires: EDIAR. 